\title{
A Rare Variation in the Veins of the Head and Neck
}

\author{
Anupama D ${ }^{1}$, R Lakshmi Prabha Subhash ${ }^{2}$, Ramesh P $^{3}$, Shivaleela $C^{4}$, BS Suresh $^{1}$ \\ ${ }^{1}$ Professor, ${ }^{2}$ Professor \& Head, ${ }^{3}$ Ph.D Scholar, ${ }^{4}$ Associate Professor, Department of Anatomy, \\ Sri Siddhartha Medical College \& Research centre, Agalakote, Tumakuru
}

DOI -10.46319/RJMAHS.2018.v01i01.007

\section{Abstract}

The knowledge of the variations in the venous pattern of the head \& neck, which may be the cause of severe hemorrhage is very important for the Physicians, Vascular surgeons and the Intervention radiologists. During dissection for Medical students in the Department of Anatomy of Sri Siddhartha Medical College, Tumakuru, a variation in the pattern of veins of Head \&Neck was observed on the right side of a male cadaver. The facial vein presented a normal course from its origin up to the base of mandible, and then it joined with the anterior division of retromandibular vein to form the Common facial vein, which drained into a common trunk along with External jugular vein, Posterior External jugular Vein and Deep cervical veins. Common trunk opened into Subclavian vein. Sound awareness regarding the variations which involve the Facial, Subclavian, External \& Internal Jugular veins is important in vascular reconstructive facio maxillary surgeries, in surgical interventions for embolism \& catheterization procedures during which these can be easily punctured in cases of variations.

Keywords: Facial Vein (FV), external jugular vein (EJV), subclavian vein (SV), internal jugular vein (IJV), common trunk (CT), posterior external jugular vein (PEJV) \& deep cervical vein (DCV)

\section{Introduction}

Supra trochlear and Supra orbital veins near the medial angle of eye unite to form angular vein which continues as facial vein and it runs posterior to the facial artery. Facial vein then combines with anterior division of Retro mandibular vein to form Common facial vein which usually drains into Internal Jugular Vein. Posterior division of Retro mandibular vein combines with posterior auricular vein to form External jugular vein behind the angle of Mandible. It then descends obliquely superficial to the sternocleidomastoid muscle and about $4 \mathrm{cms}$ above the root of the neck, it pierces the deep fascia to end in the subclavian vein. Posterior external jugular vein begins in the occipital scalp and drains the skin and superficial muscles in the neck and opens in to External jugular vein. Deep cervical vein is formed from the suboccipital region and usually drains in to Vertebral vein. ${ }^{[1]}$ Holinshed reported that in some of the cases, the External jugular vein drains into Internal jugular vein. ${ }^{[2]}$ Bergman et al opined that the formation and the termination of the External jugular vein are variable and the usual pattern is difficult to determine. ${ }^{[3]}$ They also reported the absence and duplication of the external jugular vein. In this article, we report a case of rare anatomical variation in the superficial veins of head $\&$ neck on the right side of a cadaver undergoing dissection.

\section{Case report}

During dissection session for first year medical students at Sri Siddhartha Medical College, Tumakuru, an embalmed male cadaver aged about 50 years revealed a variation in the termination of External Jugular and Common Facial veins on the right side of the Head \& neck. Facial vein arose from the face, posterior to the facial artery as a continuation of Angular vein, and combined with anterior division of Retro mandibular vein to form Common facial vein. Posterior division of Retro mandibular vein combined with posterior auricular vein to form External jugular vein behind the angle of Mandible. Posterior external Jugular vein and deep cervical veins from the post auricular regions

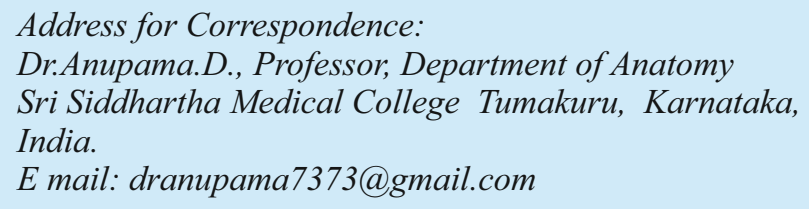




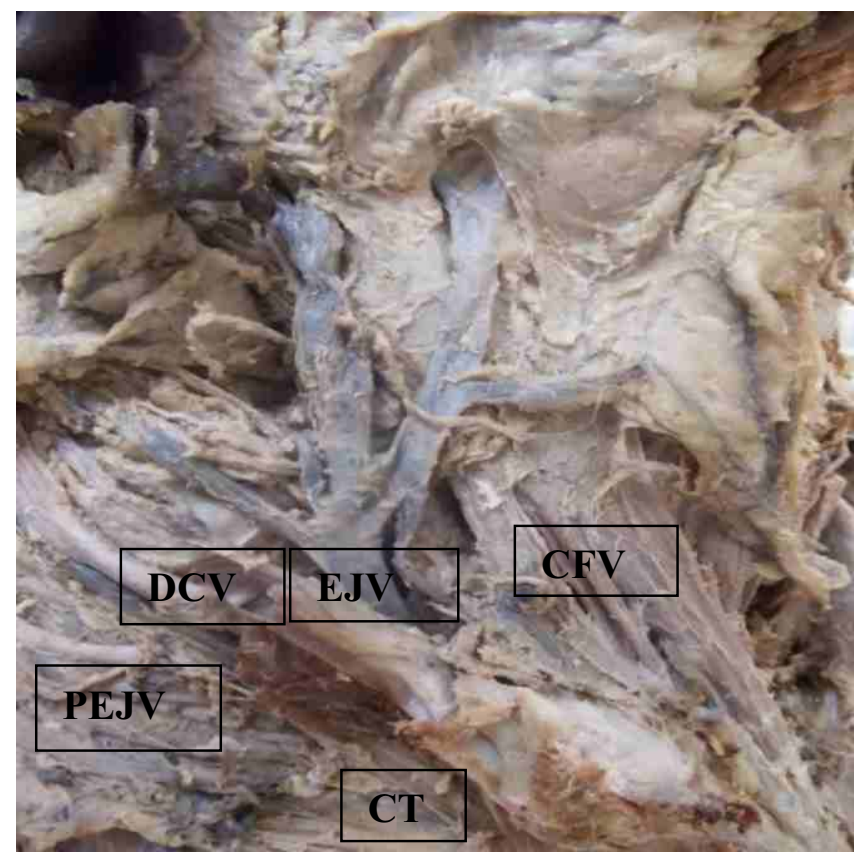

Figure 1. Anamolous common venous trunk formation

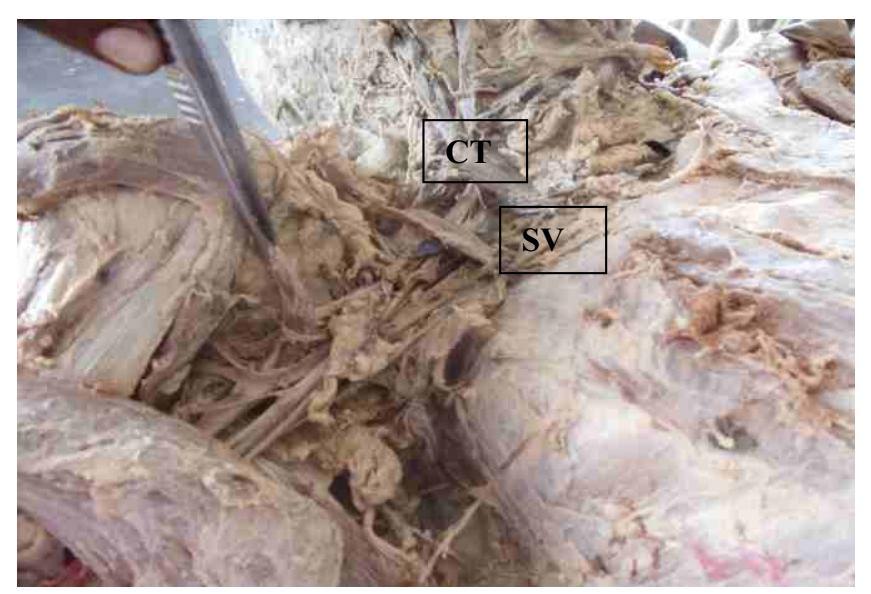

Figure 2. Common venous trunk terminating in Subclavian vein

united with the External jugular and Common facial veins in the middle of the neck to form a Common venous trunk measuring about $8 \mathrm{cms}$ in length as shown in [Figure 1] which then passed downwards to open into Subclavian vein deep to clavicle as shown in the Figure 2. The common facial vein before termination also received 2 small veins connecting it to Anterior jugular vein on the same side.

\section{Discussion}

The venous variations of the head $\&$ neck, especially the Jugular veins and subclavian veins, has gained popularity because of its common use in cannulation.
The anterior cardinal veins provide the primary venous drainage of the head during the 4th week of development and ultimately form the Internal jugular veins. External jugular vein is derived from a plexus of venous vessels in the face and drain the side of head in to Subclavian veins.$^{[4]}$ The primitive maxillary vein which drains the territory of the ophthalmic and the mandibular divisions of the trigeminal nerve including Pterygoid and temporal muscle area, anastomoses with the linguofacial vein to form the anterior facial vein. The retromandibular vein draining the temporal region, opens into the linguofacial vein to form a common trunk known as the Common facial vein, which ultimately drains into the Internal jugular vein. The External jugular vein develops as a tributary of the cephalic vein from the tissues of the neck and anastomoses secondarily with the anterior facial vein. The cephalic vein forms a venous ring around the clavicle, from which it is connected to the caudal part of the precardinal vein. The deep segment of this venous ring forms the Subclavian vein and receives the definitive External jugular vein. ${ }^{[1,4]}$ The drainage of the Common facial vein and deep cervical vein into the External jugular vein could be explained by the persistent anastomotic channel between the primitive linguofacial vein and the secondarily developing external jugular vein. These variations may not endanger the life of the patients and they are usually subclinical and are coincidental findings in surgeries, postmortem studies and dissections.

Balachandra et al described a variation of the External jugular vein and the facial vein on the right side of a cadaver in which the External jugular vein was absent and the Posterior auricular vein was draining into the Internal jugular vein. The retromandibular vein had no divisions; it was joining the facial vein to form the common facial vein which in turn was draining into the posterior auricular vein. ${ }^{[5]}$ Navneet Kumar Chauhan observed a rare unilateral variation in the formation, tributaries and drainage of External Jugular \& Facial Veins on the left side. ${ }^{[6]}$ Gupta et al described about Facial vein draining into external jugular vein in humans: its variations, phylogenetic retention and clinical relevance. They explain the anomalous venous drainage of face on the basis of regression and retention of various parts of veins as found in macaque monkeys where vein of face drain into EJV, the internal jugular 
vein being either absent or seen as a small vessel accompanying the carotid artery. ${ }^{[7]}$ Bertha $\mathrm{A}$ et al described rare bilateral drainage of the common facial vein into the subclavian vein and bilateral absence of the external jugular vein and variations in the termination of the common facial vein into the external jugular vein. ${ }^{[8]}$ This may represent a persistent communication of the primitive linguofacial vein with the secondarily developing EJV. This anastomotic channel is present for some time in the fetus but later undergoes regression. Its persistence in some individuals results in this variation. The persistence of the channels that are supposed to disappear, lead to various vascular anomalies which may complicate embolectomies and vascular reconstructive surgeries. Suhani Sumalatha D'Silva also described a common facial vein directly opening into External Jugular vein. ${ }^{[9]}$ The superficial veins, especially the external jugular vein (EJV), are increasingly being utilized for cannulation to conduct diagnostic procedures or intravenous treatment. Venipuncture is a frequent possibility in cases of variations in the patterns of superficial veins, and their knowledge is also important for surgeons doing reconstructive surgery. In every disposition there is significantly higher prevalence of unilateral rather than bilateral occurrence. Awareness of these variations could avoid unexpected injuries. Jugular veins are important for any ligations that are performed during radical neck dissection surgeries. Facial veins can be used for microvascular anastomosis in reconstruction surgeries of the head and neck. They are also used as patches for carotid endarterectomies and for oral reconstruction. ${ }^{[6]}$ Catheter placement utilizing the common facial vein is recommended for parenteral hyperalimentation and is also useful for central venous pressure monitoring. ${ }^{[10]}$ Knowledge of variant drainage of the facial vein is important to avoid inappropriate dissection which may cause severe damage.

\section{Financial support and sponsorship: Nil \\ Conflicts of interest: Nil}

\section{References}

1. Standring S. Gray's anatomy, The Anatomical Basis of the Clinical Practice. 40th ed. Spain: Churchill Livingstone Elsevier; 2008.p 451,610

2. Holinshed W H. TB of Anatomy, 3rd ed, Harper \& Row; 1974.p.407.

3. Bergman AR, Afifi KA, Miyayichi R. Compendium of Human Anatomic variations ; Urban \& Schwarzenberg, Baltimore-Munich; 1988. p 86-87.

4. Langman's Medical Embryology, 12th ed, LWW;2015.p 192

5. Balachandra N, Padmalatha K, Prakash BS and Ramesh $B R$. Variation of the veins of the head and neck - External jugular vein and facial vein. Int J Anat Var (IJAV) 2012; 5:99-101.

6. Chauhan NK, Rani A, Chopra J, Rani A, Srivastava AK, and Kumar V. Anomalous formation of External jugular vein and its clinical implication Nati J Maxillofac Surg 2011; Jan-Jun; 2(1): 51-53.

7. Gupta V, Tuli A, Choudhry R, Agarwal S, Mangal A Surg Radiol Anat 2003 Apr;25(1):36-41. Epub 2003 Jan 21.

8. Bertha A, Rabi S. Anatomical Variations In Termination OfCommon Facial Vein JCDR 2011; 5( 1): 24 - 27

9. D'Silva SS, Pulakunta T, Potu BK. Termination of the facial vein into the external jugular vein: an anatomical variation J. vasc. bras. 2008; 7(2):

10. Zumbro GL, Jr., Mullin MJ, Nelson TG: Central venous catheter placement utilizing common facial vein. A technic useful in hyperalimentation and venous pressure monitoring. Am.J.Surg. 1973 